\title{
The Ferrous Ion Chelating Assay of Pandanus Extracts
}

\author{
Nuruljannah Bt Md Yusof*, Mizaton Hazizul Hasan, Ummu Amirah Armayni, Mohd Sharil Bin \\ Ahmad, Hannis Fadzillah Mohsin \& Ibtisam Abdul Wahab
}

Faculty of Pharmacy, Universiti Teknologi MARA, 42300 Puncak Alam, Selangor, Malaysia; E-mail: joshijannah89@gmail.com

The antioxidant properties of the natural plant extracts can be resulted from their ability to chelate transition metal ions, especially $\mathrm{Fe}^{2+}$ and $\mathrm{Cu}^{2+}$. For example, the complex formation between ferrozine and $\mathrm{Fe}^{2+}$ can be disturbed by the presence of other complexing agents which cause a decrease in the red colour intensity of complexes. Phenolic compounds from Pandanus extracts (family: Pandanaceae) may consist of dihydroxy groups, which can conjugate transition metals, therefore preventing the metal-induced free radical formation. This study investigates the metal chelating capacity of Pandanus pygmaeus extracts and their column chromatographic fractions. The ferrous ion chelating (FIC) assay was performed to determine the ability of the extracts in chelating ferrous ion. The stock solution was diluted to five concentrations (1-10 $000 \mu \mathrm{g} / \mathrm{mL}) .500 \mu \mathrm{L}$ samples at different concentrations were mixed with $100 \mu \mathrm{L}$ of $0.6 \mathrm{mM}$ ferrous chloride $\left(\mathrm{FeCl}_{2}\right)$ and $900 \mu \mathrm{L}$ of methanol $(\mathrm{MeOH})$. Then, the mixtures $(1.50 \mathrm{~mL})$ were incubated for 5 minutes at room temperature. Next, $100 \mu \mathrm{L}$ of $5 \mathrm{mM}$ ferrozine was added, mixed thoroughly and left in the dark for another 10 minutes. The absorbance of the solution was measured spectrophotometrically at $562 \mathrm{~nm}$. The respective solvent used in this bioassay served as a blank control. Ethylene diamine tetraacetate (EDTA) was used as positive control. The percentage inhibition of ferrozine- $\mathrm{Fe}^{+2}$ formations was calculated. In this assay, only the MeOH extract of P. pygmaeus and positive control EDTA exhibited the chelating activity. The absorbance of ferrous and ferrozine complex was decreased dose-dependently, which means that the chelating activity was increased on increasing concentration from $1-10$ $000 \mu \mathrm{g} / \mathrm{mL}$. The highest chelating activity of $\mathrm{MeOH}$ extract and EDTA is at $10000 \mu \mathrm{g} / \mathrm{mL} \mathrm{with} 85.39 \%$ and $99.81 \%$, respectively. However, the chelating activity of $\mathrm{MeOH}$ extract still can be improved by increasing the concentration. However, compared to positive control of EDTA, $\mathrm{IC}_{50}$ of $\mathrm{MeOH}$ extract was higher than that of EDTA. The smaller the $\mathrm{IC}_{50}$ value, the higher the metal chelating activity of the compound / extract. This reveals that the MeOH extract is a moderate metal chelating agent as compared to EDTA. On the other hand, the hexane and dichloromethane extracts do not show any chelating activity as $\mathrm{IC}_{50}$ value could not be determined. The ferrous ion-chelating activity was shown by methanolic extract of $P$. pygmaeus and positive control EDTA with $\mathrm{IC}_{50}$ values $2256.50 \pm 59.53 \mu \mathrm{g} / \mathrm{mL}$ and $18.35 \pm 0.99$ and $\mu \mathrm{g} / \mathrm{mL}$, respectively.

Keywords: Chelating, ferrous ion, Pandanus. 